Published in final edited form as:

Nanomedicine. 2019 February ; 16: 217-225. doi:10.1016/j.nano.2018.12.011.

\title{
Drug-free Macromolecular Therapeutics Induce Apoptosis in Cells Isolated from Patients with B Cell Malignancies with Enhanced Apoptosis Induction by Pretreatment with Gemcitabine
}

\author{
Jiawei Wang, M.S., \\ Department of Pharmaceutics and Pharmaceutical Chemistry, University of Utah, Salt Lake City, \\ UT 84112, USA
}

Lian Li, Ph.D., Department of Pharmaceutics and Pharmaceutical Chemistry, University of Utah, Salt Lake City, UT 84112, USA

Jiyuan Yang, Ph.D., Department of Pharmaceutics and Pharmaceutical Chemistry, University of Utah, Salt Lake City, UT 84112, USA

Phillip M. Clair, B.S.,

Division of Hematology and Hematologic Malignancies and Huntsman Cancer Institute, University of Utah, Salt Lake City, UT 84112, USA

Martha J. Glenn, M.D.,

Division of Hematology and Hematologic Malignancies and Huntsman Cancer Institute, University of Utah, Salt Lake City, UT 84112, USA

Deborah M. Stephens, D.O., Division of Hematology and Hematologic Malignancies and Huntsman Cancer Institute, University of Utah, Salt Lake City, UT 84112, USA

D. Christopher Radford, B.S., Department of Biomedical Engineering, University of Utah, Salt Lake City, UT 84112, USA

\footnotetext{
*Correspondence: Jindřich Kopeček, University of Utah, Center for Controlled Chemical Delivery, 2030 East 20 South, Biopolymers Research Building, Room 205B, Salt Lake City, Utah 84112-9452, USA; jindrich.kopecek@utah.edu; Tel.: +1 (801) 581-7211; Fax: +1 (801) 581-7848.

Publisher's Disclaimer: This is a PDF file of an unedited manuscript that has been accepted for publication. As a service to our customers we are providing this early version of the manuscript. The manuscript will undergo copyediting, typesetting, and review of the resulting proof before it is published in its final citable form. Please note that during the production process errors may be discovered which could affect the content, and all legal disclaimers that apply to the journal pertain.

Conflict of interest J.Y. and J.K. are co-inventors on two pending US patent application (PCT/US2014/023784 and PCT/ US2017/37736 assigned to the University of Utah) related to this work. J.K. is Chief Scientific Advisor, J.Y. Scientific Advisor, and PJS Chief Medical Advisor for Bastion Biologics. J.K., J.Y., and P.J.S. are stockholders in Bastion Biologics.

Informed consent. All procedures followed were in accordance with the ethical standards of the responsible committee on human experimentation (institutional and national) and with the Helsinki Declaration of 1975, as revised in 2000. Informed consent was obtained from all patients for being included in the study.

* The abstract of this research was presented as a poster at the ASH annual meeting in December 2018.
} 
Ken M. Kosak, B.S., Division of Hematology and Hematologic Malignancies and Huntsman Cancer Institute, University of Utah, Salt Lake City, UT 84112, USA

Michael W. Deininger, Ph.D., M.D., Division of Hematology and Hematologic Malignancies and Huntsman Cancer Institute, University of Utah, Salt Lake City, UT 84112, USA

Paul J. Shami, M.D., and

Division of Hematology and Hematologic Malignancies and Huntsman Cancer Institute, University of Utah, Salt Lake City, UT 84112, USA

Jindřich Kopeček, Ph.D., D.Sc.

Department of Pharmaceutics and Pharmaceutical Chemistry, University of Utah, Salt Lake City, UT 84112, USA

Department of Biomedical Engineering, University of Utah, Salt Lake City, UT 84112, USA

\section{Abstract}

Drug-free macromolecular therapeutics (DFMT) is a new paradigm for the treatment of B cell malignancies. Apoptosis is initiated by the biorecognition of complementary oligonucleotide motifs at the cell surface resulting in crosslinking of CD20 receptors. DMFT is composed from two nanoconjugates: 1) bispecific engager, Fab'-MORF1 (anti-CD20 Fab' fragment conjugated with morpholino oligonucleotide), and 2) a crosslinking (effector) component P-(MORF2) $\mathrm{X}(\mathrm{N}-(2-$ hydroxypropyl)methacrylamide (HPMA) copolymer grafted with multiple copies of complementary morpholino oligonucleotide). We evaluated this concept in 44 samples isolated from patients diagnosed with various subtypes of B cell malignancies. Apoptosis was observed in $65.9 \%$ of the samples tested. Pretreatment of cells with gemcitabine (GEM) or polymergemcitabine conjugate (2P-GEM) enhanced CD20 expression levels thus increasing apoptosis induced by DFMT. These positive results demonstrated that DFMT has remarkable therapeutic potential in various subtypes of B cell malignancies.

\section{Graphical abstract}

Drug-free macromolecular therapeutics (DFMT) is a new paradigm for the treatment of B cell malignancies. Apoptosis is initiated by crosslinking of CD20 receptors triggered by the biorecognition of complementary oligonucleotide motifs at the cell surface. The therapeutic efficacy of DFMT on 44 primary patient samples with various B-cell malignancies has been evaluated. Pretreatment of cells with gemcitabine or polymer-gemcitabine conjugate enhanced CD20 expression and increased levels of apoptosis. The results indicate that DFMT has significant translational potential.

\section{Keywords}

Drug-free macromolecular therapeutics; B cell lymphoma; CD20; apoptosis; nanomedicine 


\section{Background}

Treatment of Non-Hodgkin lymphoma is challenging as the disease comprises over 35 different subtypes with the most prevalent types being diffuse large B cell lymphoma (DLBCL), follicular lymphoma (FL) and mantle cell lymphoma (ML). ${ }^{1}$ The majority of NHLs (85\%) are of B cell origin, and more than $95 \%$ of B cell lymphomas bear the cell surface antigen CD20, one of the most reliable biomarkers and therapeutic targets for B cells. ${ }^{2}$ Rituximab (RTX), the first anti-CD20 monoclonal antibody approved by FDA for clinical use in 1997, initiated a new era for treatment of B cell NHLs. ${ }^{3}$ Its combination with chemotherapy can further enhance the therapeutic activity and still remains mainstay of therapy in young and fit patients. ${ }^{4}$ With the development of new, more active modern chemotherapy protocols and targeted therapies, much progress has been made over the past two decades. ${ }^{5}$ Unfortunately, relapsed or resistant disease is still a major cause of treatment failure. $^{6}$

Recently we have developed a new paradigm for the treatment of B cell malignancies, drugfree macromolecular therapeutics (DFMT),${ }^{7-13}$ which initiates apoptosis by the biorecognition of a pair of complementary motifs at the cell surface resulting in crosslinking of CD20 receptors. As no toxin or cytotoxic agent is involved, DFMT does not induce the side effects of traditional chemotherapy. The effectiveness of this innovative crosslinking CD20 approach has been proven in vitro ${ }^{8-11}$ and in vivo. ${ }^{8,9,12}$ Preliminary results with patient cells have been also published, ${ }^{12,13}$ in which Fab' fragment of 1F5 anti-CD20 monoclonal antibody (mAb) conjugated with a 25-base pair morpholino oligonucleotide (Fab ${ }_{1 F 5}$-MORF1) was administered to patient cells as bispecific engager, then a crosslinking effector composed of $\mathrm{N}$-(2-hydroxypropyl)methacrylamide (HPMA) copolymer grafted with multiple copies of complementary morpholino oligonucleotide P-(MORF2)X was used to crosslink CD20 via hybridization of MORF1/MORF2 and trigger B cell apoptosis. Human serum albumin conjugated with MORF2 is also under investigation to perform as a crosslinking effector. ${ }^{14}$

Chronic lymphocytic leukemia (CLL), the most common form of adult leukemia is usually a slowly progressive disease of autoreactive mature B cells. Normally, these tumor cells have low sensitivity to anti-CD20 mAbs. ${ }^{15}$ Although many CLL cases have an indolent course, there is considerable heterogeneity and some patients rapidly transform into aggressive lymphomas. ${ }^{16}$ Various somatic mutations and the mutational status of immunoglobulin heavy chain variable genes (IGHV) have been associated with outcome. Non-mutated IGHV is associated with a worse outcome. Genomic aberrations often observed are $17 \mathrm{p}$ deletion (17p-), 11q deletion (11q), trisomy 12 (+12), 13q deletion (13q-), and others. ${ }^{17}$ Mutations of NOTCH1 and SF3B1 are also observed with relatively high frequency in CLL patients. ${ }^{18}$ Currently, standard first-line therapies for CLL include chemoimmunotherapy that incorporate anti-CD20 $\mathrm{mAb}$, or targeted therapies, depending on risk factors. We have previously shown that that DFMT-based CD20 receptor crosslinking system is cytotoxic to CLL cells and has advantages over current cytotoxic therapies and immunotherapies. ${ }^{13}$ Moreover, we found that pre-incubation of CD20-low expression RTX-resistant B cells with gemcitabine upregulated CD20 level and enhanced apoptosis. ${ }^{9,19}$ Interestingly, the CD20 enhancement appeared to be time-dependent but not concentration-dependent. Consequently, 
we hypothesized that in vivo a long circulating HPMA copolymer - gemcitabine conjugate $(2 \mathrm{P}-\mathrm{GEM})^{20}$ should be more efficient than free gemcitabine. Indeed, we validated this hypothesis in an animal model of NHL. ${ }^{9}$

Herein we evaluated the efficacy of DFMT on a large group of primary tumor cells from patients with various $\mathrm{B}$ cell lymphomas $(\mathrm{N}=9)$ or CLL $(\mathrm{N}=35)$, including a variety of genotypes. We also tested whether combined gemcitabine with DFMT will enhance therapeutic efficacy in the patient cells with low CD20 expression. Our results suggest that DFMT has significant activity against CLL cells with a spectrum of somatic mutations and that gemcitabine pretreatment may enhance efficacy of CD20-targeted therapies in B-cell malignancies with low CD20 expression.

\section{Methods}

\section{Patient samples}

Malignant B cells were isolated from patients diagnosed by the hematologic malignancies service at the Huntsman Cancer Institute. All patients provided informed consent to a research protocol approved by the University of Utah Institutional Review Board (IRB\#45880). Samples P1 - P9 were cryopreserved and samples P10 - P44 were fresh.

\section{Nanoconjugates}

Fab'-MORF1, Cy5-labeled Fab'-MORF1, P-(MORF2) ${ }_{9.5}$, and Cy3-labeled P-(MORF2) 9.5 nanoconjugates were synthesized and characterized as previously reported. ${ }^{8,10}$ Two types of Fab'-MORF1 were used, derived from 1F5 (chimera mouse anti-CD20 mAb) and RTX, respectively.

\section{Determination of CD20 Expression}

Cell surface CD20 expression was determined by flow cytometry. Cells $\left(2 \times 10^{5}\right)$ were treated with $0.5 \mu \mathrm{M}$ rituximab for $1 \mathrm{~h}$ at $4{ }^{\circ} \mathrm{C}$ followed by goat-anti-human (GAH) secondary antibody conjugated with AlexaFluor-488 (1:500 dilution). Incubation time was $20 \mathrm{~min}$ at room temperature. Cells were washed and re-suspended in PBS prior to flow cytometry analysis. Cells treated only with fluorescence-labeled secondary antibody were used as negative controls.

\section{Induction of Apoptosis}

Cells $\left(2 \times 10^{5}\right)$ were suspended in RPMI-1640 medium (Sigma, St. Louis, MO) supplemented with $10 \%$ fetal bovine serum (Hyclone, Logan, UT). Incubation was carried out at $37{ }^{\circ} \mathrm{C}$ in a humidified atmosphere with $5 \% \mathrm{CO}_{2}$.

Cells were treated with Fab'-MORF1 and P-MORF2 at $1 \mu \mathrm{M}$ equivalent MORF1/MORF2 concentration consecutively ( $1 \mathrm{~h}$ interval). For samples P1-P6, Fab' derived from 1F5 mAb (chimera mouse anti-CD20 mAb) was used. In this case, 1F5 and goat-anti-mouse (GAM) secondary antibody (KPL, Gaithersburg, MD) were used for comparison. For samples P7P44 Fab' from RTX was used. For comparison, $0.5 \mu \mathrm{M}$ RTX (equal Fab' concentration with Fab'-MORF1) hyper-crosslinked with $0.25 \mu \mathrm{M}$ goat-anti-human (GAH) secondary antibody 
(KPL, Gaithersburg, MD) was used. Cells treated with PBS were used as negative controls. Cells were incubated with treatment at $37^{\circ} \mathrm{C}$ for $20 \mathrm{~h}$. All experiments were conducted in duplicate or triplicate, depending on the number of cells available.

\section{Annexin V/propidium iodide (PI) staining}

Cells $\left(2 \times 10^{5}\right)$ were suspended in $0.4 \mathrm{~mL}$ medium for different treatments as indicated. Harvested cells were washed twice with PBS prior to staining with propidium iodide (PI) and FITC-conjugated Annexin V (Oncogene Research Products, Boston, MA) for $15 \mathrm{~min}$ at room temperature, protected from light, followed by flow cytometry analysis. For gemcitabine pretreatment, cells were pretreated with $500 \mathrm{ng} / \mathrm{mL}$ gemcitabine (or gemcitabine equivalent in 2P-GEM) in RPMI-1640 medium for $48 \mathrm{~h}$ at $37{ }^{\circ} \mathrm{C}$ and washed with PBS before treatment as described above.

\section{Caspase-3 Activity Measurement}

Cells $\left(2 \times 10^{5}\right)$ were suspended in $0.4 \mathrm{~mL}$ medium for DFMT or RTX/GAH treatment. Cells were incubated at $37{ }^{\circ} \mathrm{C}$ with $5 \% \mathrm{CO}_{2}$ for indicated time periods. Harvested cells were washed twice with PBS prior to resuspension in $50 \mu \mathrm{L}$ caspase 3 solution (PhiPhiLux kit, OncoImmunin, Gaithersburg, MD) and incubation at $37^{\circ} \mathrm{C}$ for $1 \mathrm{~h}$. Caspase 3 activity was measured according to the manufacturer's protocol.

\section{Cell Cycle Analysis}

Cells were washed twice with PBS after the indicated treatment and permeabilized in 70\% ethanol overnight. Cells were stained with excess PI in PBS, and DNA content was determined by flow cytometry.

\section{Mitochondrial Membrane Potential Analysis}

CLL patient cells $\left(2 \times 10^{5}\right)$ were used for different treatments as described. Cells were washed with PBS and re-suspended in $100 \mu \mathrm{L}$ PBS. Two $\mu \mathrm{L}$ of $200 \mu \mathrm{M} \mathrm{JC}-1(1 \mathrm{H}-$ benzimidazolium, 5,6-dichloro-2-[3-(5,6-dichloro-1,3-diethyl-1,3-dihydro-2Hbenzimidazol-2-ylidene)-1-propenyl]-1,3-diethyl-, iodide) was added and incubated with cells at $37{ }^{\circ} \mathrm{C}$ for $30 \mathrm{~min}$. JC-1 is a mitochondrial membrane potential sensor (Thermo Scientific). As a positive control, $1 \mu \mathrm{L}$ of $50 \mathrm{mM} \mathrm{CCCP}$ (carbonyl cyanide $m$ chlorophenylhydrazone) was added and incubated simultaneously with JC-1 for $30 \mathrm{~min}$. Cells were then washed and re-suspended in PBS followed by flow cytometry analysis using $488 \mathrm{~nm}$ excitation with 520/30 nm and 585/42 band-pass filters.

\section{Bcl-2 Expression Detection}

CLL patient cells $\left(2 \times 10^{5}\right)$ were used for different treatments as indicated. After treatment, cells were fixed with $4 \%$ paraformaldehyde for $15 \mathrm{~min}$ at room temperature followed by permeabilization with $90 \%$ methanol for 30 min on ice. Anti-Bcl-2 mAb labeled with AlexaFluor 488 (1:500, Santa Cruz Biotechnology) was used for cell immunostaining in $0.5 \%$ bovine serum albumin (BSA) buffer for $1 \mathrm{~h}$ at room temperature. After washing with PBS, fluorescence was quantified using flow cytometry analysis. 


\section{Confocal Microscopy}

Patient CLL cells $\left(2 \times 10^{5}\right)$ were treated with $1 \mu \mathrm{M}$ Fab'-MORF1-Cy5 for $1 \mathrm{~h}$. Cells were then washed with PBS and further incubated with $1 \mu \mathrm{M}$ P-MORF2-Cy3 for $1 \mathrm{~h}$. Afterwards cells were washed with PBS and re-suspended in PBS in 4-well chambers (MatTek Corporation) prior to confocal visualization (Olympus laser scanning confocal microscope, FV1000). For the control group, cells were pretreated with 10-fold excess of RTX for $1 \mathrm{~h}$ before Fab'-MORF1/P-MORF2 treatment described in previous publication ${ }^{8}$.

\section{Statistical analysis}

All experiments were conducted in duplicate or triplicate, depending on the number of cells available. Data are presented as mean \pm standard deviation (SD). Differences were considered significant for $P$ values $<0.05$ using the Student's $t$ test.

\section{Results}

The efficacy of drug-free macromolecular therapeutics (DFMT) was assessed in 44 samples including $35 \mathrm{CLL}$ along with other B cell lymphomas such as diffuse large B cell lymphoma (DLBCL), marginal zone lymphoma (MZL), follicular lymphoma (FL), mantle cell lymphoma (MCL) etc (Table 1). The isolated cells were treated with Fab'-MORF1 and P-

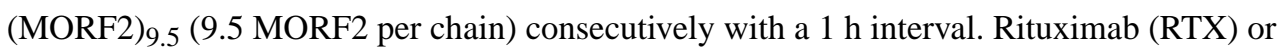
1F5 were used to produce Fab' fragments for Fab'-MORF1 synthesis. In all treatments, conjugates were added at a concentration of $1 \mu \mathrm{M}$ Fab' equivalent $(0.5 \mu \mathrm{M}$ of $\mathrm{mAb})$. Results of apoptosis assays are summarized in Table 2. P1-P6 cells were treated with Fab' ${ }_{(1 F 5)^{-}}$ MORF1/P-(MORF2) 9.5 while P7-P44 cells were treated with Fab' ${ }_{(\mathrm{RTX})}$-MORF1/P(MORF2) 9.5. Patients P1-P9 had various B cell lymphomas while patients P10-P44 had chronic lymphocytic leukemia (CLL). In samples P1-P9, DFMT showed significant efficacy in inducing apoptosis compared to controls in all samples except for samples P5 and P6. In samples P2, P4, P7 and P9, DFMT showed superior efficacy at apoptosis induction compared to RTX treatment. P4 and P9 were MCL samples. P1, P3 and P5 were DLBCL samples. P6 and P8 were MZL samples, while P2 was a FL sample. All MCL samples responded to DFMT treatment while 2 of 3 samples of DLBCL responded to DFMT treatment. One MZL sample and one FL responded to DFMT treatment. These results demonstrated that DFMT strategy works on different types of B-cell lymphoma tested here.

Regarding CLL samples, a variety of chromosomal abnormalities, including 17p13 deletion $(\mathrm{N}=4), 11 \mathrm{q} 22$ deletion $(\mathrm{N}=3)$, and 13q14 deletion $(\mathrm{N}=25)$ have been observed. Altogether Fab' $_{(\mathrm{RTX})}$-MORF1/P-(MORF2) 9.5 induced cell apoptosis effectively in $65.9 \%$ of samples (Table 2).

When sufficient cells were available, a detailed evaluation of apoptosis induction by DFMT was performed. A typical example such an analysis is shown in Figure 1 (Sample P12). In that analysis, we evaluated surface CD20 expression (Fig. 1A), plasma membrane rupture (Fig. 1B), caspase 3 activation (Fig. 1C), genomic DNA fragmentation (Fig. 1D), mitochondrial membrane permeabilization (Fig. 1E), and Bcl-2 inhibition (Fig. 1F). Also, confocal imaging was used to document specific biorecognition at the cell surface, first 
biorecognition of Fab'-MORF1 by CD20 followed by biorecognition/hybridization of MORF1/MORF2 (Fig 1G). The results showed that DFMT was effective on inducing apoptosis (Fig. 1B-F). The high CD20 expression in sample P12 was associated with a substantially increased response to DFMT treatment (Table 2). As shown in Fig. 1B, cell population shifted from left lower zone to right lower zone tremendously demonstrating significantly increased cell apoptosis. Cell cycle assay (Fig. 1D) also showed that with DFMT and RTX/GAH treatment, more cells were trapped in Sub G1 phase indicating increased amount of apoptotic cells. Especially in the group treated with DFMT, the number of apoptotic cells was nearly twice higher than that treated with RTX/GAH. Decreased expression of anti-apoptotic protein Bcl-2 was observed with treatment of DFMT and RTX/ $\mathrm{GAH}$, respectively (Fig. 1F), showing that inhibition of Bcl-2 is involved in the apoptosis induction mechanism of DFMT treatment. Confocal imaging (Fig. 1G) showed biorecognition events and colocalization of the two nanoconjugates at the cell surface. Specificity of binding to CD20 was demonstrated by blocking self-assembly at the cell using pre-treatment with excess RTX.

Our results suggest that DFMT has therapeutic potential for different types of B-cell malignancies. Statistical analysis shows that the level of surface CD20 expression is an important factor affecting therapeutic efficacy. Additional work with a larger set of patient samples from various diagnoses is needed to identify other critical features that are important in the response to CD20 targeting and to identify subsets of patients suitable for DFMT treatment.

A promising strategy to further improve the therapeutic efficacy of DFMT is to use gemcitabine pretreatment. GEM is used to treat different types of malignancies and can lead to accumulation of cells in S phase. ${ }^{22}$ Importantly, GEM was shown to increase CD20 expression level in B cells. ${ }^{19}$ As CD20 expression level is a critical factor affecting the therapeutic efficacy of antiCD20 therapy, combination of CD20-targeting therapy with GEM could potentially increase the efficacy of the DFMT. We pre-treated cells from samples P40, P42 and P43 for $48 \mathrm{~h}$ with GEM at $500 \mathrm{ng} / \mathrm{mL}$ as these samples had low CD20 expression levels. Cells were then washed and treated with DFMT as well as RTX/GAH. GEM pretreatment significantly increased CD20 expression compared to controls without GEM pretreatment (Fig. 2A, 2C). Representative results of flow cytometry showed increased apoptosis (Fig. 2D). Correspondingly, statistical analysis showed increased apoptosis level cells with GEM pretreatment (Fig. 2B). Alternatively, P26 cells were pretreated with a longcirculating HPMA copolymer-GEM conjugate (2P-GEM). Cells pretreated with 2P-GEM showed higher CD20 expression as well as increased apoptosis levels (Fig. 2E, 2F).

\section{Discussion}

B cell malignancies affect millions of people worldwide with significant morbidity and mortality. The DFMT B cell depletion strategy is able to avoid the adverse effects induced by rituximab treatment with promising therapeutic efficacy. Data presented here validate that DFMT treatment has therapeutic potential against a wide variety of B cell lymphoma subtypes. In many samples, DFMT showed statistically significant increases in apoptosis when compared to RTX/GAH, indicating that the proposed treatment could have better 
therapeutic efficacy, at least in certain cases. However, in several samples, DFMT showed only comparable or even or lower efficacy. Different factors may be at play, including differences in the level of expression of CD20. Expression level of CD20 was the dominant strength in determination of therapeutic potential of treatments. Patient samples with high CD20 expression levels were more likely to show increased apoptosis following treatment with DFMT. The higher the CD20 expression level, the better the therapeutic efficacy of the treatment as shown in Figure 3.

Genomic aberration is also a factor affecting traditional therapies. The most common cytogenetic mutation in CLL is deletion of 13q14, detected in around 50\% of CLL patients. ${ }^{23}$ It might not be sufficient to be considered an adverse prognostic factor. ${ }^{24}$ However, 13q14 deletion is a critical genomic aberration for increased apoptotic resistance. The 13q14 region is usually described as a negative regulator of the anti-apoptotic protein Bcl-2. ${ }^{24}$ Mutation of this region increases the expression of Bcl-2, allowing CLL cells to survive, resulting in lower apoptosis levels induced by treatment. The incidence of $17 \mathrm{p}$ deletion in CLL patients is close to $10 \%$ and is associated with an inferior prognosis. ${ }^{23}$ The $17 \mathrm{p} 13$ region is involved in important regulatory functions. Its deletion is believed to be a strong independent marker in evaluating death caused by disease. p53 tumor suppressor gene is deleted in patients with $17 \mathrm{p} 13$ deletion. P53 deficiency may allow cells to survive from therapeutic treatment as p53dependent apoptosis pathway is interrupted. ${ }^{23}$ Deletion of 11q occurs in $10-20 \%$ of CLL patients. ${ }^{25}$ The 11q22 region is involved in activation of p53-dependent apoptosis pathway thus its loss leads to reduced cell death. ${ }^{23}$ Combination of deletions of $17 \mathrm{p}$ and $11 \mathrm{q}$ are considered as significantly poorer prognoses. ${ }^{26} \mathrm{We}$ evaluated 25 primary patient samples with 13q14 deletion, 4 samples with 17p13 deletion and 3 samples with 11q22 deletion. Previously, we had shown that DFMT induced efficient CD20 crosslinking-mediated apoptosis in patient cells with $17 \mathrm{p} 13$ deletion. ${ }^{13}$ International prognostic index (IPI) is used in clinics to predict outcome of individual patients based on patient's clinical characteristics including genomic aberrations. Higher IPI values indicate more problems in treatment. Based on the results summarized in Table 2 with patient information in Table 1, therapeutic efficacy of our DFMT treatment on CLL primary patient samples varied regarding to similar genomic aberrations. Seven samples with different mutations were selected for evaluation (Figs. 3A and 3B). Fig. 3A shows that the higher the CD20 expression level, the higher the DMFT mediated apoptosis induction. Fig. 3B demonstrates that the value of IPI does not hamper the efficacy of DFMT. For example, both samples P18 and P31 have 13q14 and 17p dual deletions. IPI of P18 is 4 while IPI of P31 is 7, indicating a worse outcome prediction of sample P31. However, DFMT exhibited superior apoptosis induction in P31 sample over P18 sample, demonstrating that CD20 expression level is the determinant factor affecting therapeutic efficacy of DFMT. Similar phenomena were observed in P39 and P43 patient samples with IPI score of 3 . With the same IPI score, DFMT showed much higher efficiency in apoptosis induction in P39 compared to P43 as P39 possessed a higher CD20 expression level. It seems that CD20 expression level could overcome the anti-apoptotic effect involved with critical deletions.

It appears that it is essential to increase CD20 expression level to improve therapeutic efficacy of DFMT treatment. Exposure to gemcitabine was reported to increase CD20 expression level. ${ }^{22}$ The increase in CD20 expression resulted from gemcitabine-induced NF- 
$\kappa \mathrm{B}$ activation as NF- $\mathrm{\kappa B}$ binds to the $\mathrm{CD} 20$ promoter to induce $\mathrm{CD} 20$ transcriptional activation. ${ }^{9,15}$ With patient samples P26, P40, P42 and P43, cells were pretreated with GEM or 2P-GEM. Figure 2 shows that pretreatment with GEM or polymer conjugated GEM (2PGEM) increases expression level of CD20 receptor significantly, thus increasing the efficacy of DFMT in inducing apoptosis. These results support the observation that CD20 expression level is the key factor for DFMT treatment efficacy. Combination therapy of DFMT with GEM would be a promising strategy to improve its therapeutic efficacy in insensitive samples. More work is needed to confirm the potential increased efficacy of the combination of GEM with CD20-targeted therapy. In addition, comprehensive studies will be conducted with GEM and 2P-GEM pretreatment on patient cells, CD20+ B cell lines, and on animal models to assure the feasibility of combination strategy.

In summary, apoptosis induction by DFMT in primary cells from patients with various B cell malignancies was evaluated. DFMT effectively increased apoptosis of tumor cells from patients with a variety of B cell malignancies, irrespective of genomic aberrations. In CLL samples, the CD20 expression level is positively correlated with susceptibility to DFMTinduced apoptosis. Pretreatment with GEM or HPMA copolymer-GEM conjugate improved DFMT therapeutic efficacy in poorly responding samples, likely due to increased CD20 expression. With increased CD20 expression, DFMT treatment is able to overcome the antiapoptotic effect involved in critical genomic aberrations. The results suggest that DFMT is a promising modality for the treatment of different B cell malignancies. Especially with RTXresistant B cell malignancies, combination therapy of DFMT with GEM provides a prospective solution to overcome drug resistance. In addition, crosslinking of receptors as a design principle for novel therapeutic approaches is applicable to other receptors such as CD79b, ${ }^{27}$ prostate stem cell antigen, ${ }^{28}$ and DR5. ${ }^{29}$

\section{Acknowledgments}

The work was supported in part by NIH grant RO1 GM95606 (to JK) from the National Institute of General Medical Sciences, Huntsman Cancer Institute (award No. 180303), and the University of Utah Research Foundation. We acknowledge support of funds from grant P30 CS042014 awarded to Huntsman Cancer Institute and to the ET Program at Huntsman Cancer Institute.

\section{Abbreviations}

DFMT

MORF

HPMA

GAH

GAM

2P-GEM drug-free macromolecular therapeutics morpholino oligonucleotide

$N$-(2-hydroxypropyl)methacrylamide

goat-anti-human

goat-anti-mouse

backbone degradable HPMA polymer-gemcitabine conjugate 


\section{References}

1. Stashenko P, Nadler LM, Hardy R, Schlossman SF. Characterization of a human B lymphocytespecific antigen. J Immunol 1980;125:1678-85. [PubMed: 6157744]

2. Maloney DG. Anti-CD20 antibody therapy for B-cell lymphomas. New Engl J Med 2012;366:200816. [PubMed: 22621628]

3. Okroj M, Österborg A, Blom AM. Effector mechanisms of anti-CD20 monoclonal antibodies in B cell malignancies. Cancer Treat Rev 2013;39:632-9. [PubMed: 23219151]

4. Hofmeister JK, Cooney D, Coggeshall KM. Clustered CD20 induced apoptosis: src-family kinase, the proximal regulator of tyrosine phosphorylation, calcium influx, and caspase 3-dependent apoptosis. Blood Cells, Molecules \& Diseases 2000;26:133-43.

5. Johnson RN, Kopečková P, Kopeček J. Biological activity of anti-CD20 multivalent HPMA copolymer-Fab' conjugates. Biomacromolecules 2012;13:727-35. [PubMed: 22288884]

6. Deans JP, Li H, Polyak MJ. CD20-mediated apoptosis: signaling through lipid rafts. Immunology 2002;107:176-82. [PubMed: 12383196]

7. Yang J, Li L, Kopeček J. Biorecognition: A key to drug-free macromolecular therapeutics. Biomaterials 2019;190-191:11-23.

8. Chu TW, Yang J, Zhang R, Sima M, Kopeček J. Cell surface self-assembly of hybrid nanoconjugates via oligonucleotide hybridization induces apoptosis. ACS Nano 2014;8:719-30. [PubMed: 24308267]

9. Li L, Yang J, Wang J, Kopeček J. Amplification of CD20 crosslinking in Rituximab-resistant Blymphoma cells enhances apoptosis induction by drug-free macromolecular therapeutics. ACS Nano 2018;12:3658-70. [PubMed: 29595951]

10. Li L, Yang J, Wang J, Kopeček J. Drug-free macromolecular therapeutics induce apoptosis via calcium influx and mitochondrial signaling pathway. Macromol Biosci 2018;18:1700196.

11. Zhang L, Fang Y, Yang J, Kopeček J. Drug-free macromolecular therapeutics: Impact of structure on induction of apoptosis in Raji B cells. J Control Release 2017;263:139-50. [PubMed: 28024916]

12. Chu TW, Zhang R, Yang J, Chao MP, Shami PJ, Kopeček J. A Two-step pretargeted nanotherapy for CD20 crosslinking may achieve superior anti-lymphoma efficacy to Rituximab. Theranostics 2015;5:834-46. [PubMed: 26000056]

13. Chu TW, Kosak KM, Shami PJ, Kopeček J. Drug-free macromolecular therapeutics induce apoptosis of patient chronic lymphocytic leukemia cells. Drug Deliv Transl Res 2014;4:389-94. [PubMed: 25580376]

14. Zhang L, Fang Y, Li L, Yang J, Radford DC, Kopeček J. Human serum albumin based drug-free macromolecular therapeutics: Apoptosis induction by coiled-coil-mediated crosslinking of CD20 antigens on lymphoma B cell surface. Macromol Biosci 2018;18:1800224.

15. Wiestner A The role of B-cell receptor inhibitors in the treatment of patients with chronic lymphocytic leukemia. Haematologica 2015;100:1495-507. [PubMed: 26628631]

16. Niederhuber JE, Armitage JO, Doroshow JH, Kastan MB, Tepper JE. Non-Hodgkin lymphoma Roschewski MJ, Wilson WH, editors. Abeloff's clinical oncology. 5th ed Philadelphia: Elsevier; 2014, p. 2033-59.

17. Döhner H, Stilgenbauer S, Benner A, Leupolt E, Kröber A, Bullinger L, Döhner K, Bentz M, Lichter P. Genomic aberrations and survival in chronic lymphocytic leukemia. New Engl J Med 2000;343:1910-6. [PubMed: 11136261]

18. Stilgenbauer S, Schnaiter A, Paschka P, Zenz T, Rossi M, Döhner K, and 26 others. Gene mutations and treatment outcome in chronic lymphocytic leukemia: results from the CLL8 trial. Blood 2014;123:3247-54. [PubMed: 24652989]

19. Hayashi K, Nagasaki E, Kan S, Ito M, Kamata Y, Homma S, Alba K. Gemcitabine enhances rituximab-mediated complement-dependent cytotoxicity to B cell lymphoma by CD20 upregulation. Cancer Sci 2016;107:682-9. [PubMed: 26920337]

20. Zhang R, Yang J, Sima M, Zhou Y, Kopeček J. Sequential combination therapy of ovarian cancer with degradable $\mathrm{N}$-(2-hydroxypropyl)methacrylamide copolymer paclitaxel and gemcitabine conjugates. Proc Natl Acad Sci U S A 2014;111:12181-6. [PubMed: 25092316] 
21. The International CLL-IPI working group. An International prognostic index for patients with chronic lymphocytic leukaemia (CLL-IPI): a meta-analysis of individual patient data. Lancet Oncol 2016;17:779-90 [PubMed: 27185642]

22. Smith MR, Joshi I, Jin F, Obasaju C. Enhanced efficacy of gemcitabine in combination with antiCD20 monoclonal antibody against CD20+ non-Hodgkin's lymphoma cell lines in vitro and in SCID mice. BMC Cancer 2005;5:103. [PubMed: 16109167]

23. Mehes G Chromosome abnormalities with prognostic impact in B-cell chronic lymphocytic leukemia. Pathol Oncol Res 2005;11:205-10. [PubMed: 16388316]

24. Grygalewicz B, Woroniecka R, Rygier J, Borkowska K, Rzepecka I, Lukasik M, Budziłowska A, Rymkiewicz G, Błachnio K, Nowakowska B, Bartnik M, Gos M, Pieńkowska-Grela B.

Monoallelic and biallelic deletions of 13q14 in a group of CLL/SLL patients investigated by CGH haematological cancer and SNP array (8×60K). Mol Cytogenetics 2016;9:1.

25. Jiang Y, Chen HC, Su X, Thompson PA, Liu X, Do KA, et al. ATM function and its relationship with ATM gene mutations in chronic lymphocytic leukemia with the recurrent deletion (11q22.323.2). Blood Cancer J 2016;6:e465. [PubMed: 27588518]

26. Greipp PT, Smoley SA, Viswanatha DS, Frederick LS, Rabe KG, Sharma RG, et al. Patients with chronic lymphocytic leukaemia and clonal deletion of both $17 \mathrm{p} 13.1$ and 11q22.3 have a very poor prognosis. Brit J Haematol 2013;163:326-33. [PubMed: 24032430]

27. Brühl H, Cihak J, Talke Y, Gomez Rodriguez M, Hermann F, Goebel N, Renner K, Plachý J, Stangassinger M, Aschermann S, Nimmerjahn F, Mack M. B-cell inhibition by cross-linking $\mathrm{CD} 79 \mathrm{~b}$ is superior to B-cell depletion with anti-CD20 antibodies in treating murine collageninduced arthritis. Eur J Immunol 2015;45:705-15. [PubMed: 25471597]

28. Gu Z, Yamashiro J, Kono E, Reiter RE, Anti-prostate stem cell antigen monoclonal antibody 1G8 induces cell death in vitro and inhibits tumor growth in vivo via a Fc-independent mechanism. Cancer Res 2005;65:9495-500. [PubMed: 16230414]

29. Wajant H, Moosmayer D, Wuest T, Bartke T, Gerlach E, Schonherr U, Peters N, Schurich P, Pfizenmaier K. Differential activation of TRAIL-R1 and -2 by soluble and membrane TRAIL allows selective surface antigen-directed activation of TRAIL-R 2 by a soluble TRAIL derivative. Oncogene 2001;20:4101-6. [PubMed: 11494138] 
A.

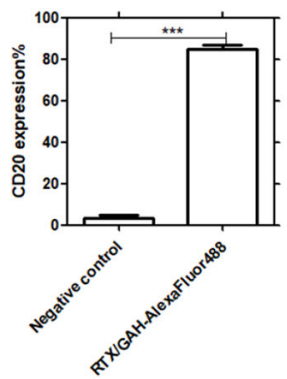

B.

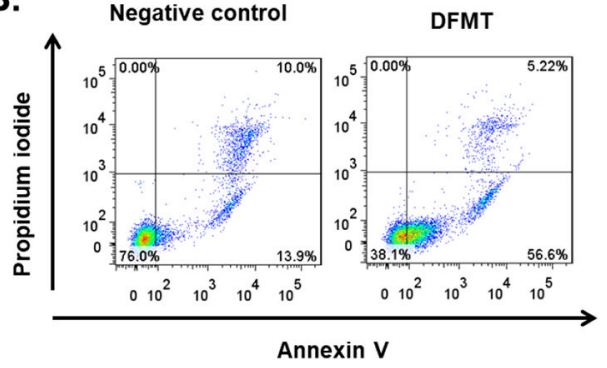

C.

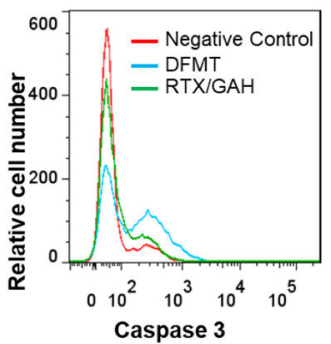

D.
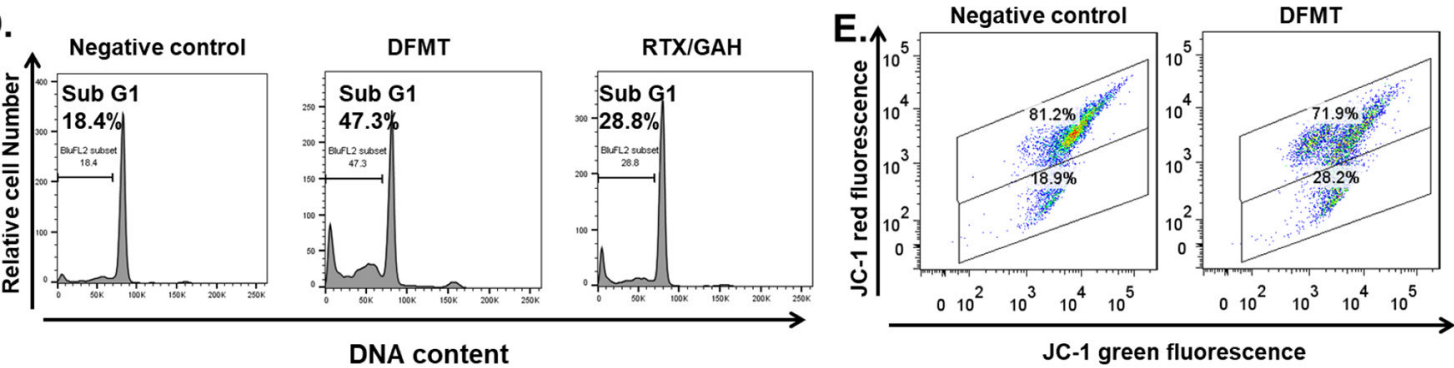

$\mathbf{F}$.
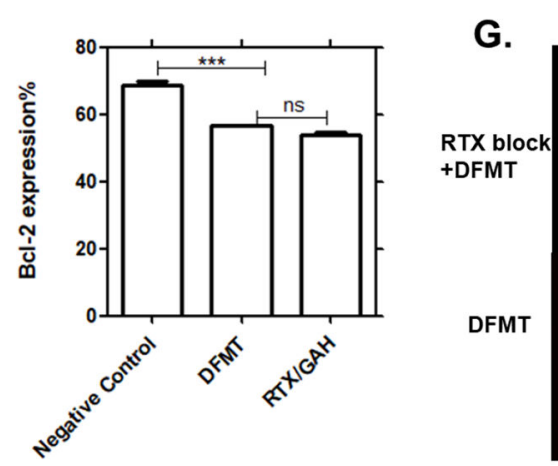

Fab'-MORF1-Cy5

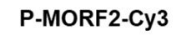

Overlap

Figure 1.

Drug-free macromolecular therapeutics induced apoptosis of CLL cells from P12. Negative control, cells treated with PBS; DFMT, Fab'-MORF1 $(1 \mu \mathrm{M})$ followed (1 h later) by P(MORF2) $9.5(1 \mu \mathrm{M}$; MORF2 eqv); RTX/GAH, RTX $(0.5 \mu \mathrm{M})$ followed (1 h later) by GAH $(0.25 \mu \mathrm{M})(\mathbf{A})$ Cell surface CD20 expression as determined by fluorescent-labeled antibody. Negative control, cells treated with only GAHAlexaFluor 488 ; $R T X / G A H$-AlexaFluor 488 , RTX $(0.5 \mu \mathrm{M})$ followed (1 h later) by GAH-AlexaFluor488 (1:200). Incubation time was 20 min. (B) Representative flow cytometry analysis of cells exposed to different treatments (incubation time $20 \mathrm{~h}$ ) and stained by PI and FITC-labeled Annexin V. (C) Representative flow cytometry analysis of cells exposed to different treatments (incubation time $6 \mathrm{~h}$ ) and stained by FITC-labeled anti-active Caspase-3 Ab. (D) Cell cycle analysis. After exposed to different treatments (incubation time $6 \mathrm{~h}$ ), cells were permeabilized and stained by PI to measure DNA content. SubG1 phase represents apoptotic cells. (E) Mitochondrial membrane potential determined by JC-1 fluorescence. Incubation time was $6 \mathrm{~h}$. After treatment, $4 \mu \mathrm{M}$ JC-1 was added to all samples. (F) Bcl-2 expression as determined by Alexa-fluor488-labeled rabbit anti-Bcl-2 Ab. Incubation time was $6 \mathrm{~h}$. After treatment, Alexa-fluor488-labeled anti-Bcl-2 Ab was added to all samples (1:50). (G) Confocal imaging. RTX block, cells were treated with RTX $(10 \mu \mathrm{M})$ for $1 \mathrm{~h}$ followed by regular 
DFMT treatment. Fab'-MORF1 was labeled by Cy5 while P-(MORF2) 9.5 was labeled by Cy3. (***p< $0.001, n s$, no significant difference; Student's t test). 
A.

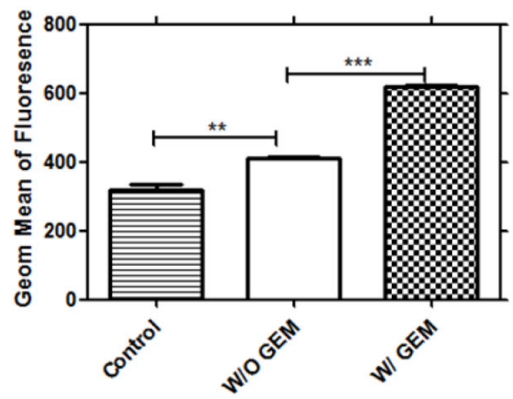

c.

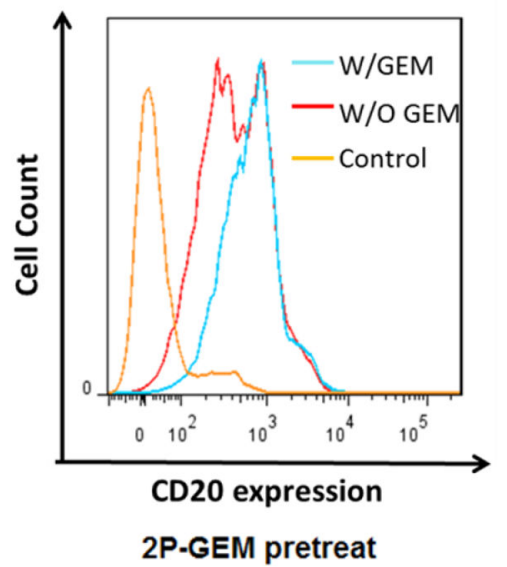

E.

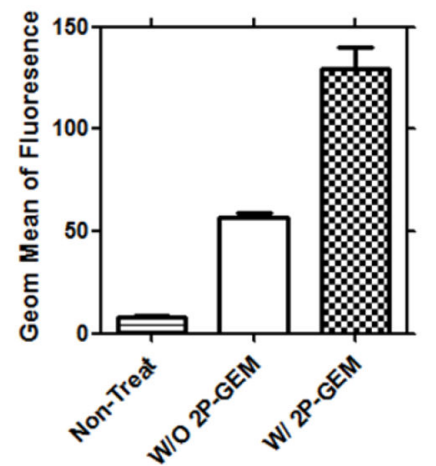

B.

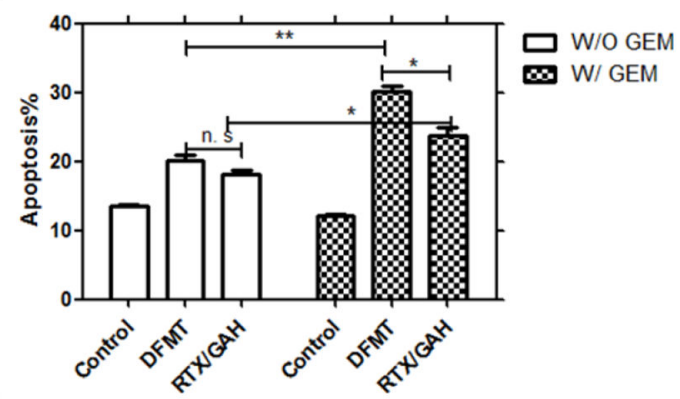

D.

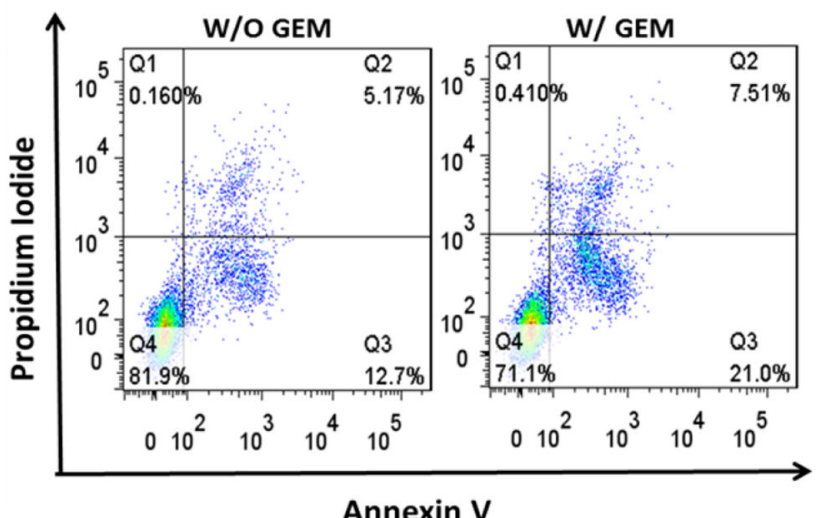

F.

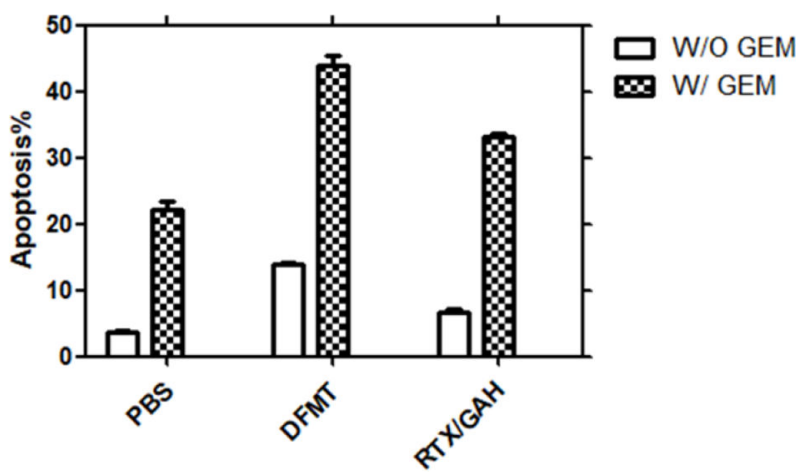

Figure 2.

Pretreatment with GEM or 2P-GEM increases apoptosis efficacy. (A-D) P40; (E-F) P26. Pretreatment with GEM or 2P-GEM: Cells were treated with $500 \mathrm{ng} / \mathrm{ml}$ GEM or GEM equivalent at $37^{\circ} \mathrm{C}$ for $48 \mathrm{~h}$ before DFMT treatment; Negative control, cells treated with PBS; DFMT, Fab'-MORF1 $(1 \mu \mathrm{M})$ followed (1 h later) by P-(MORF2) $)_{9.5}(1 \mu \mathrm{M}$; MORF2 eqv); $R T X / G A H$, RTX $(0.5 \mu \mathrm{M})$ followed (1 h later) by GAH $(0.25 \mu \mathrm{M})(\mathbf{A})$ Cell surface CD20 expression as determined by fluorescence-labeled antibody. Negative control, cells treated with GAH-AlexaFluor488 only; $R T X / G A H$, RTX $(0.5 \mu \mathrm{M})$ followed (1 h later) by GAH-AlexaFluor488 (1:200). Incubation time was $20 \mathrm{~min}$. (B) Apoptosis efficacy was increased in all the treatment groups after GEM pretreatment. Incubation was 24 h. (C) Representative flow cytometry analysis of CD20 expression on cell surface with or without GEM pretreatment. (D) Representative flow cytometry analysis of cells treated by DFMT therapy with or without GEM pretreatment. (E) Cell surface CD20 expression with or 
without 2P-GEM pretreatment. (F) Apoptosis efficacy increased in all treatment groups after 2P-GEM pretreatment. (*** $\mathrm{p}<0.001, n s$, no significant difference; Student's t test). 
A.

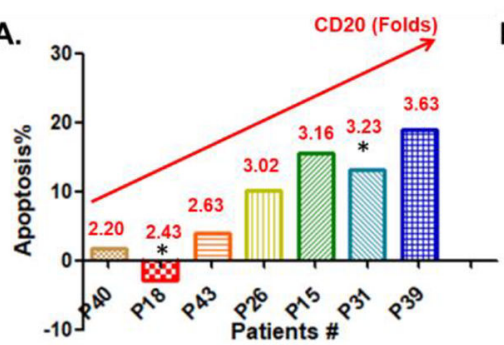

B.

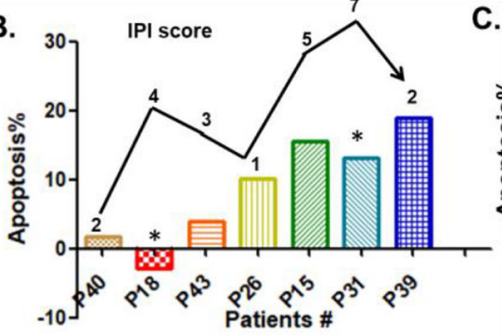

C.

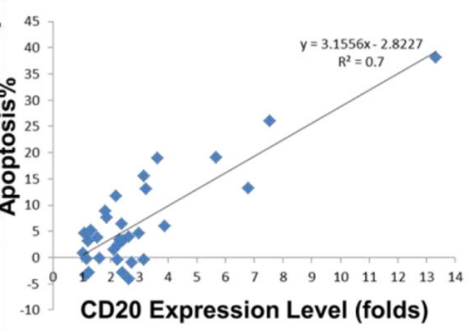

Figure 3.

Correlations between apoptosis level (\%) and CD20 expression level / International Prognostic Index (IPI). (A \& B) Selected samples with various genomic aberrations. * Samples with $17 \mathrm{p}$ deletion. (A) Relationship between level of apoptosis induction and CD20 expression. (B) IPI score does not affect efficacy of DFMT in samples with genomic aberrations. (C) Correlation between increased apoptosis level (\%) and CD20 expression level in P10-P44 samples. 
Table 1.

Clinical Characteristics of Lymphoma Patients

\begin{tabular}{|c|c|c|c|c|c|c|c|c|}
\hline Patient & ${ }^{a}$ Gender & Age & $b_{\text {Diagnosis }}$ & ${ }^{c}$ IPI score & $13 q 14$ & $11 q 22$ & $17 \mathbf{p}$ & $d_{\text {Pretreat }}$ \\
\hline $\mathrm{P} 1$ & $\mathrm{~F}$ & 66 & BCL,BETWEEN & & & & & \\
\hline $\mathrm{P} 2$ & $\mathrm{~F}$ & 53 & FL & & & & & \\
\hline P3 & $\mathrm{F}$ & 53 & LBCL & & & & & \\
\hline P4 & M & 67 & MCL & & & & & \\
\hline P5 & $\mathrm{F}$ & 21 & DLBCL & & & & & Frozen Samples \\
\hline P6 & $\mathrm{F}$ & 70 & SMZL & & & & & \\
\hline P7 & N/A & N/A & N/A & & & & & \\
\hline P8 & $\mathrm{F}$ & 81 & SMZL & & & & & \\
\hline P9 & M & 67 & MCL & & & & & \\
\hline P10 & $\mathrm{F}$ & 87 & CLL & 4 & Yes & No & No & Chlorambucil + Rituximab \\
\hline P11 & M & 80 & CLL & 6 & N/A & N/A & No & None \\
\hline $\mathrm{P} 12$ & N/A & N/A & CLL & $\mathrm{N} / \mathrm{A}$ & N/A & N/A & N/A & None \\
\hline $\mathrm{P} 13$ & M & 59 & CLL & 0 & Yes & No & No & None \\
\hline P14 & $\mathrm{F}$ & 66 & CLL & 1 & Yes & No & No & None \\
\hline P15 & M & 78 & CLL & $4-6$ & Yes & No & No & None \\
\hline P16 & M & 66 & CLL & 4 & Yes & No & No & None \\
\hline P17 & F & 58 & CLL & 0 & Yes & No & No & None \\
\hline P18 & M & 60 & CLL & 4 & Yes & No & Yes & None \\
\hline P19 & M & 72 & CLL & 4 & Yes & No & No & None \\
\hline $\mathrm{P} 20$ & F & 63 & CLL & $3-5$ & Yes & No & No & None \\
\hline $\mathrm{P} 21$ & M & 85 & CLL & 6 & Yes & Yes & No & None \\
\hline $\mathrm{P} 22$ & M & 60 & CLL & 5 & Yes & No & No & BR-Ibrutinib \\
\hline $\mathrm{P} 23$ & M & 69 & CLL & 2 & N/A & N/A & No & FCR \\
\hline P24 & M & 59 & CLL & 0 & Yes & No & No & None \\
\hline $\mathrm{P} 25$ & M & 56 & CLL & 0 & N/A & N/A & No & None \\
\hline $\mathrm{P} 26$ & F & 48 & CLL & 1 & Yes & No & No & None \\
\hline P27 & M & 74 & CLL & 1 & Yes & No & No & None \\
\hline $\mathrm{P} 28$ & F & 55 & CLL & 1 & Yes & No & No & None \\
\hline P29 & M & 65 & CLL & 2 & No & No & No & None \\
\hline P30 & M & 79 & CLL & 1 & Yes & No & No & None \\
\hline $\mathrm{P} 31$ & $\mathrm{~F}$ & 65 & CLL & 7 & Yes & No & Yes & Iburutinib-Obino-CVP-Idelalisib-Venetoclax-BI836826 \\
\hline P32 & M & 80 & CLL & 6 & No & No & No & None \\
\hline P33 & M & 79 & CLL & $4-6$ & Yes & No & No & None \\
\hline P34 & M & 58 & CLL & 1 & N/A & N/A & No & None \\
\hline P35 & M & 70 & CLL & 4 & Yes & No & No & Ibrutinib \\
\hline P36 & $\mathrm{F}$ & 45 & CLL & 1 & No & No & No & None \\
\hline P37 & M & 62 & CLL & 7 & Yes & Yes & Yes & None \\
\hline P38 & F & 63 & CLL & 0 & Yes & No & No & None \\
\hline
\end{tabular}




\begin{tabular}{ccccccccc}
\hline Patient & $\boldsymbol{a}_{\text {Gender }}$ & Age & $\boldsymbol{b}_{\text {Diagnosis }}$ & $\boldsymbol{c}_{\text {IPI score }}$ & $\mathbf{1 3 q 1 4}$ & $\mathbf{1 1 q 2 2}$ & $\mathbf{1 7 p}$ & $\boldsymbol{d}_{\text {Pretreat }}$ \\
\hline P39 & F & 77 & CLL & $1-3$ & Yes & No & No & None \\
P40 & F & 73 & CLL & $1-3$ & Yes & No & No & None \\
P41 & F & 52 & CLL & 2 & N/A & N/A & No & None \\
P42 & F & 63 & CLL & 5 & N/A & N/A & Yes & None \\
P43 & F & 65 & CLL & 3 & Yes & Yes & No & None \\
P44 & M & 71 & CLL & 2 & Yes & Yes & No & None \\
\hline
\end{tabular}

${ }^{a}$ M male; F female

${ }^{b}$ Abbreviations: BCL (B-Cell Lymphoma Unclassifiable), DLBCL (Diffuse Large B-Cell lymphoma), BL (Burkett Lymphoma), FL (Follicular Lymphoma), LBCL (Large B-Cell Lymphoma), MCL (Mantle Cell Lymphoma), SMZL (Splenic Marginal Zone Lymphoma), CLL (Chronic Lymphocytic Leukemia

c. IPI: International Prognostic Index (IPI). Low risk (score 0-1); Intermediate risk (score 2-3); High risk (score 4-6); Very-high risk (score 7$10)^{21}$

d. Abbreviations: BR (Bendamustine and rituximab); FCR (Cyclophosphaminde, fludarabine and rituximab); FR (Fludarabine and rituximab); CVP (Cyclophosphaminde, vincristine sulfate and prednisone) 
Table 2.

Experimental Results of Apoptosis Assays

\begin{tabular}{|c|c|c|c|c|}
\hline \multirow{2}{*}{ Patient \# } & \multirow{2}{*}{ CD20 expression } & \multirow{2}{*}{ Pretreatment } & \multicolumn{2}{|c|}{ Increased Apoptosis\% ${ }^{\#}$} \\
\hline & & & DFMT $^{\# 1}$ & RTX/GAH ${ }^{\# 2}$ \\
\hline P1 & & - & $31.09^{*}$ & $36.97^{*}$ \\
\hline $\mathrm{P} 2$ & & - & $4.37^{* * *}$ & $1.67^{*}$ \\
\hline P3 & & - & $16.56^{*}$ & $18.13^{*}$ \\
\hline P4 & & - & $11.26^{* *}$ & 2.99 \\
\hline P5 & N/A & - & 1.27 & -3.17 \\
\hline P6 & & - & 10.24 & 8.9 \\
\hline P7 & & - & $9.09^{* *}$ & $6.09^{*}$ \\
\hline P8 & & - & $12.17^{*}$ & $15.24^{*}$ \\
\hline P9 & & - & $17^{* *}$ & $5.1^{*}$ \\
\hline P37 & 1.05 & - & 0.78 & $11.68^{*}$ \\
\hline P28 & 1.10 & - & $4.56^{*}$ & $18.23^{*}$ \\
\hline P35 & 1.14 & - & -3.36 & -4.59 \\
\hline P13 & 1.18 & - & -1.33 & 0.44 \\
\hline P27 & 1.22 & - & $3.12^{*}$ & $15.4^{*}$ \\
\hline P38 & 1.24 & - & -2.88 & -1.15 \\
\hline \multirow[t]{2}{*}{ P42 } & 1.26 & - & $4.79^{*}$ & $10.96^{*}$ \\
\hline & 1.51 & Pretreat with GEM & $11.94 *$ & $12.6^{*}$ \\
\hline P29 & 1.32 & - & $5.2^{*}$ & $15.84^{*}$ \\
\hline P34 & 1.55 & - & $3.82^{*}$ & $14.71^{*}$ \\
\hline P22 & 1.62 & - & -0.16 & 0.62 \\
\hline P17 & 1.81 & - & $8.8^{*}$ & $15.87^{*}$ \\
\hline $\mathrm{P} 14$ & 1.87 & - & $7.64^{*}$ & $9.72 *$ \\
\hline P30 & 2.12 & - & 1.45 & -0.05 \\
\hline \multirow[t]{2}{*}{ P40 } & 2.20 & - & $1.67^{*}$ & -0.4 \\
\hline & 3.30 & Pretreat with GEM & $17.97^{* *}$ & $11.57^{*}$ \\
\hline P19 & 2.24 & - & -0.42 & $22.94^{*}$ \\
\hline P33 & 2.28 & - & 2.5 & 0.12 \\
\hline P36 & 2.31 & - & $3.37^{*}$ & $12.29^{*}$ \\
\hline $\mathrm{P} 10$ & 2.39 & - & 6.38 & $21.4^{*}$ \\
\hline P18 & 2.43 & - & -2.93 & 1.75 \\
\hline P16 & 2.45 & - & 3.2 & 1.34 \\
\hline \multirow[t]{2}{*}{ P43 } & 2.63 & - & $3.89^{*}$ & $34.23 *$ \\
\hline & 3.05 & Pretreat with GEM & $23.47^{*}$ & $40.77^{*}$ \\
\hline
\end{tabular}

Nanomedicine. Author manuscript; available in PMC 2020 February 01. 


\begin{tabular}{|c|c|c|c|c|}
\hline \multirow{2}{*}{ Patient \# } & \multirow{2}{*}{ CD20 expression } & \multirow{2}{*}{ Pretreatment } & \multicolumn{2}{|c|}{ Increased Apoptosis\% ${ }^{\#}$} \\
\hline & & & DFMT $^{\# 1}$ & RTX/GAH ${ }^{\# 2}$ \\
\hline $\mathrm{P} 20$ & 2.64 & - & -4.09 & $27.94^{*}$ \\
\hline $\mathrm{P} 24$ & 2.73 & - & -0.99 & $25.79^{*}$ \\
\hline P11 & 3.00 & - & $4.63^{*}$ & $17.11^{*}$ \\
\hline $\mathrm{P} 15$ & 3.16 & - & $15.55^{* *}$ & $9.67^{*}$ \\
\hline $\mathrm{P} 23$ & 3.17 & - & -0.36 & $4.12^{*}$ \\
\hline P31 & 3.23 & - & $13.1^{*}$ & $13.96^{*}$ \\
\hline P39 & 3.63 & - & $18.95^{* *}$ & -6.42 \\
\hline $\mathrm{P} 21$ & 3.89 & - & $5.97^{*}$ & $21.88^{*}$ \\
\hline P44 & 4.18 & - & $49^{* *}$ & $39.5^{*}$ \\
\hline P41 & 5.67 & - & $19.07^{* *}$ & $4.78^{*}$ \\
\hline \multirow[t]{2}{*}{ P26 } & 6.80 & - & $10.11^{* *}$ & $2.94^{*}$ \\
\hline & 15.60 & Pretreat with 2P-GEM & $21.61^{* *}$ & $10.97^{*}$ \\
\hline $\mathrm{P} 25$ & 7.55 & - & $10.4^{* * *}$ & $2.97^{*}$ \\
\hline P12 & 13.31 & - & $38.13^{* *}$ & $28.35^{*}$ \\
\hline P32 & N/A & - & $22.51^{*}$ & $25.07^{*}$ \\
\hline
\end{tabular}

GEM: Gemcitabine

2P-GEM: Backbone degradable HPMA copolymer-gemcitabine conjugate

P10-P44 were sorted by CD20 expression levels

All samples were tested with Annexin V assay (except samples P4 and P40 that were tested tested with Caspase 3 assay)

\# Increased Apoptosis\%: Apoptosis level achieved after subtraction of value of negative control group

\#1 DFMT: samples were treated by Fab'-MORF1 followed by P-MORF2

\#2 RTX/GAH: samples were treated by RTX followed by goat-anti-human $2^{\text {nd }}$ antibody

Significantly higher than Negative Control $(\mathrm{P}<0.05$; Student's t test $)$

** Significantly higher than Negative Control and RTX/GAH ( $\mathrm{P}<0.05$; Student's t test) 